\title{
Combined use of free vascularised fibula graft and extracorporeally irradiated osteochondral graft for osteosarcoma of the proximal ulna
}

\author{
AKIRA OGOSE $^{1}$, TETSUO HOTTA ${ }^{1}$, MINORU SHIBATA $^{2}$, HIROYUKI KAWASHIMA $^{1}$ and NAOTO ENDO $^{1}$ \\ ${ }^{1}$ Division of Orthopedic Surgery, Graduate School of Medical and Dental Sciences, Niigata University; \\ ${ }^{2}$ Division of Plastic Surgery, Niigata University Hospital, Niigata, Japan
}

Received March 31, 2009; Accepted August 6, 2009

DOI: 10.3892/ol_00000024

\begin{abstract}
The elbow is an uncommon site for malignant bone tumors. Surgical options for the reconstruction of the elbow joint are limited and technically challenging. In this study, we describe a patient with osteosarcoma of the proximal ulna treated by wide resection and reconstruction with a combined use of free vascularised fibula graft and extracorporeally irradiated osteochondral graft. Ten years after the surgery, the patient is alive, without disease and is able to play golf with no lateral instability or pain of the elbow joint. A vascularised fibula, combined with extracorporeally irradiated osteochondral graft with ligamentous repair is one of the options for the treatment of malignant bone tumor of the proximal ulna.
\end{abstract}

\section{Introduction}

The elbow is an uncommon site for malignant bone tumors. Since the introduction of limb-spearing surgery and adjuvant chemotherapy, reconstruction of the elbow after resection of malignant tumors has became an alternative to amputation. However, surgical options for reconstruction of the elbow are limited and technically challenging (1-6).

Arthrodesis of the elbow results in restricted motion and excisional arthroplasty may result in instability (7). Allografts have been used, but with a high complication rate (8).

The case of a man with osteosarcoma of the proximal ulna that was excised and reconstructed using a combination of extracorporeally irradiated osteochondral autograft and free vascularised fibula is presented. He has remained free of

Correspondence to: Dr Akira Ogose, Division of Orthopedic Surgery, Graduate School of Medical and Dental Sciences, Niigata University, Asahimachi 1-751, Niigata 951-8510, Japan

E-mail: aogose@med.niigata-u.ac.jp

Key words: vascularised fibula, osteosarcoma, proximal ulna disease with excellent function of the affected area 10 years after surgery.

\section{Case Report}

A 48-year old male was referred to us with an enlarged hard mass in his left elbow. It had been present for 6 months. A physical examination revealed a bony hard lump, $5 \times 6 \mathrm{~cm}$ in size, in the posterior aspect of the proximal forearm. Radiography and CT showed a heavily mineralized tumor of the proximal ulna (Fig. 1). Magnetic resonance imaging demonstrated an intramedullary tumor extending to the posterior soft tissue. Open biopsy was perfromed and low-grade osteosarcoma was diagnozed. During surgery, the left proximal ulna was approached via anterior and posterior incisions. After osteotomy of the mid shaft, $13 \mathrm{~cm}$ of the proximal ulna were resected along with the flexor digitorum profundus muscle, the flexor carpi ulnaris muscle, ulnar collateral ligament and ulnar half of annular ligament. Tendinous insertions of the brachialis and triceps were transected. Resected ulna and soft tissue were placed in a small plastic box filled with saline, and the box was administered with a single dose of $60 \mathrm{~Gy}$. The irradiated graft was returned to the operating theater. The distal $7 \mathrm{~cm}$ of the resected ulna was osteotomized and the intramedullary tumor of the olecranon was curetted. The vascularised fibula was inserted into the medullary cavity of the olecranon and fixed with screws. The ligaments and tendinous insertion of the brachialis and triceps were sutured. Then, distal osteosynthesis was carried out with a plate and screws. The donor peroneal vessels were side-anastomosed to the ulnar vessels (Fig. 2). Fixation with a cast was applied for 4 weeks and an additional functional hinged-brace was applied for 3 months. Histological examination of the resected tumor showed low-grade osteosarcoma with small foci of high-grade components. The patient was given 3 courses of chemotherapy consisting of ifosfamide and doxorubicin. The iliac cancellous bone graft for proximal non-union site was added 16 months after the initial surgery. Ten years after the initial surgery the patient has recuperated and shows no evidence of disease (Fig. 3). The appearance and elbow function are excellent (extension-flexion, -20/120; 


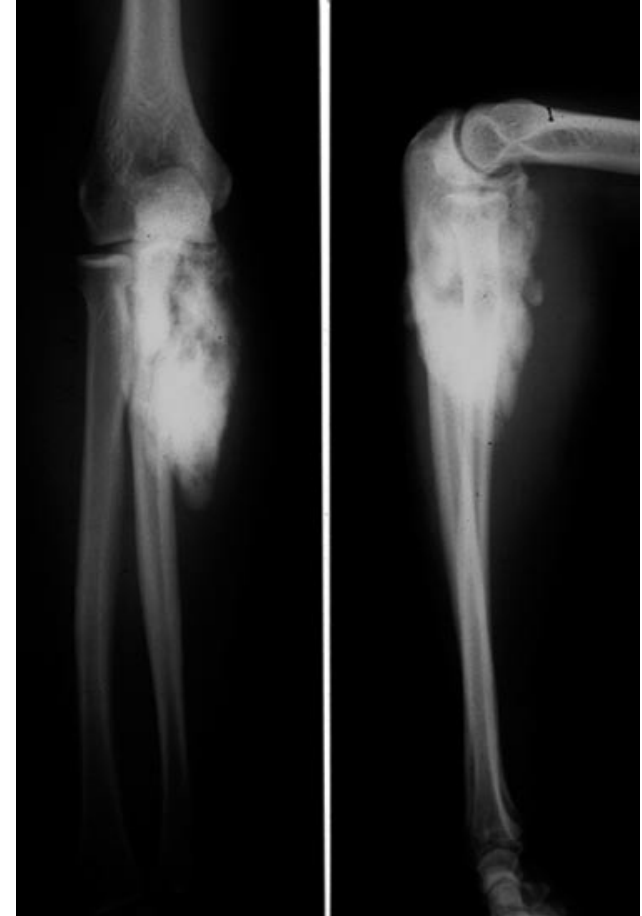

Figure 1. Plain radiographs showing sclerotic bone tumor of the proximal ulna.

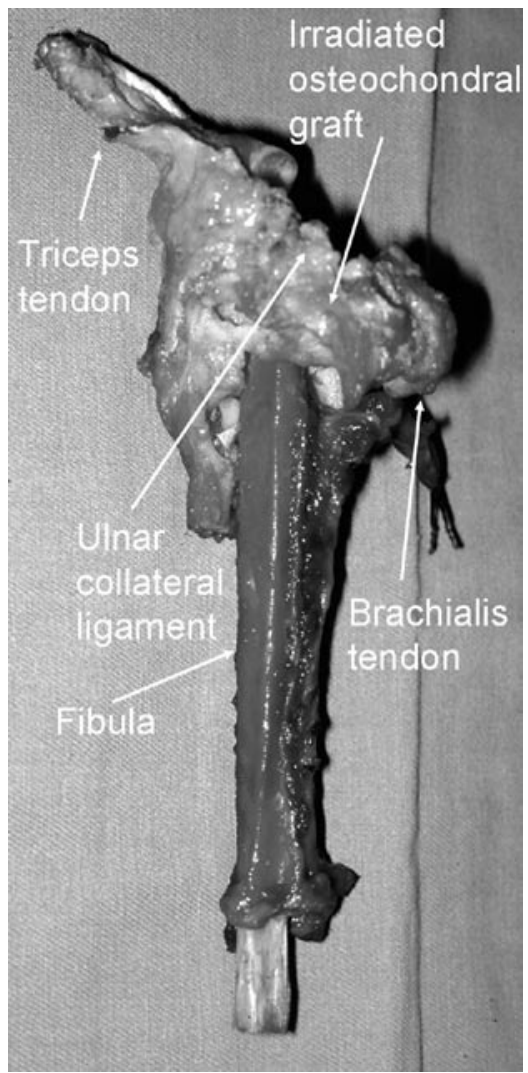

Figure 2. Extracorporeally irradiated osteochondral graft with ligaments and tendons was connected to vascularised fibula.

pronation, 80; supination 10) (Fig. 4). The patient is able to play golf with no lateral instability or pain of the elbow joint.

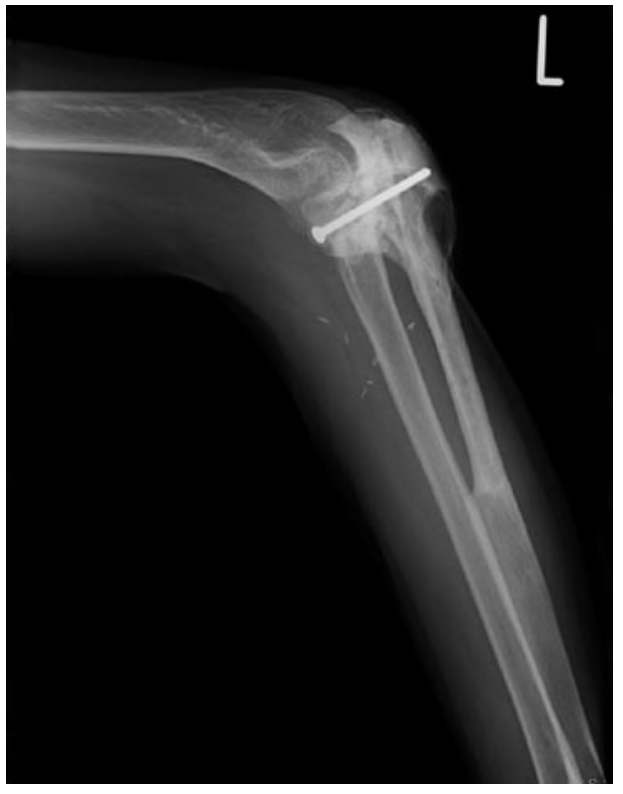

Figure 3. Radiographs taken 10 years after the surgery.

A

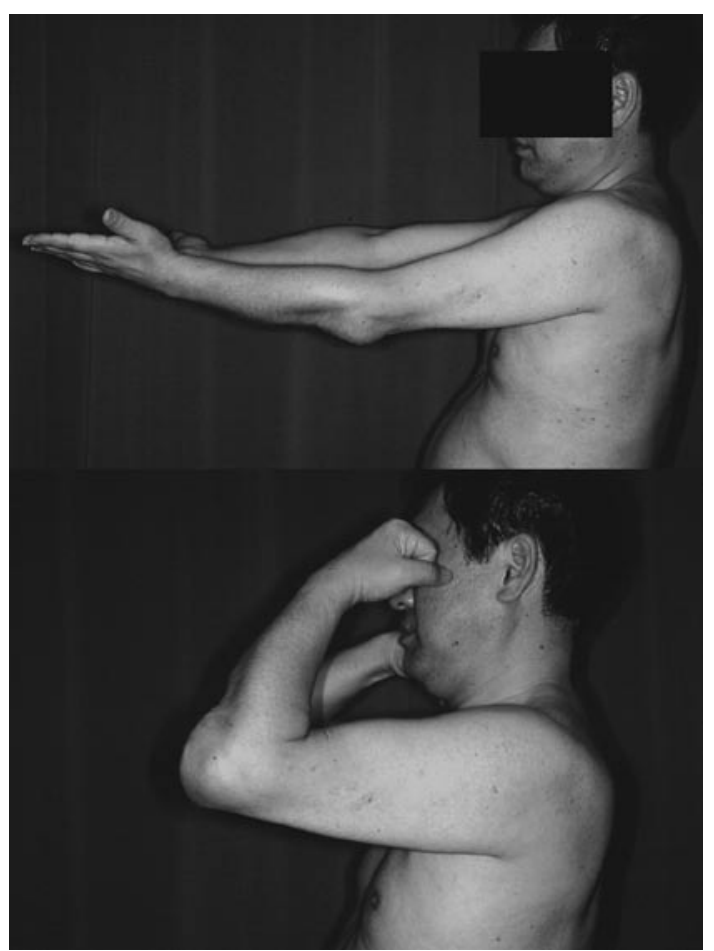

Figure 4. Images of the upper limb with (A) extension and (B) flexion.

\section{Discussion}

Although satisfactory results of endoprosthetic reconstruction for elbow tumors have been reported, such studies mainly described humeral bone tumors. Endoprosthetic reconstruction of a large defect of the proximal ulna is not well established (1-6). We found only two cases of endoprosthetic reconstruction for malignant bone tumor of the proximal ulna $(2,3)$. 
However, clinical details, including long-standing durability, were not reported.

Elbow allografts appear to be another option. However, elbow allografts have been associated with a high risk of infection and joint degeneration. Dean et al reported that complications occurred in 16 of 23 patients treated with allograft implantations for massive bone loss of the elbow. They concluded that elbow allografts were not recommended for routine use of elbow surgery (8).

Gianoutsos et al reported a case of adamantinoma of the proximal ulna treated with en bloc excision and vascularised fibular graft. The patient had remained free of disease with good function of the elbow (flexion-extension, 10-100 ${ }^{\circ}$ ) 3 years after surgery. However, the elbow joint was subluxated and the instability of the elbow joint was not mentioned (9).

Kimura et al also reported excellent results with 4-year follow-up periods of a case of Ewing sarcoma at the proximal ulna treated with vascularised fibular graft. They grafted a fibular head with the biceps femoris tendon and the fibular ligament. The biceps femoris tendon was sutured to the annular ligament and the fibular collateral ligament was sutured to the tendon of the triceps muscle. The functional results were excellent with active movement of the elbow from 5 to $150^{\circ}$, but joint stability of the elbow was not reported (10).

Extracorporeal irradiation of tissue followed by reimplantation can be used to replace bone defects following removal of tumors (11-19). One of the advantages of irradiated bone for reconstructive surgery is the possibility of achieved good joint function, especially where the ligamentous tissues have been preserved, since the ligaments of the patient can be restored to their original shape, size and site (12). However, the complication rate of this reconstruction, including nonunion, infection and fracture was high (12-16). Recently, favorable results of the combined use of vascularised bone graft and extracorporeally irradiated bone for reconstruction have been reported $(18,19)$. This approach has the advantage of combining the biological properties provided by the vascularised bone graft with the mechanical endurance of the irradiated osteochondral graft.

In the present case, since the tumor occurred in the proximal site of the ulna, the ulna had to be excised along with the joint surface, elbow ligaments and tendons. In order to reconstruct the elbow joint, we used irradiated osteochondral and soft tissue graft with vascularised fibular graft to enhance the neovascularization of irradiated tissue. Although iliac bone graft for the non-union of the proximal osteosynthetic site was necessary, long-standing joint stability was excellent. Some degree of articular change clearly occurs after irradiated osteochondral graft (18). Further follow-up of this patient is needed to monitor the risk of severe joint degeneration.

In conclusion, a vascularised fibula, combined with extracorporeally irradiated osteochondral graft, with ligamentous repair, is one of the options for the treatment of malignant bone tumor of the proximal ulna.

\section{References}

1. Ross AC, Sneath RS and Scales JT: Endoprosthetic replacement of the humerus and elbow joint. J Bone Joint Surg 69-B: 652-653, 1987.

2. Weber KL, Lin PP and Yasko AW: Complex segmental elbow reconstruction after tumor resection. Clin Orthop 415: 31-44, 2003.

3. Sperling JS, Prichard DJ and Morrey BF: Total elbow arthroplasty after resection of tumors at the elbow. Clin Orthop 367: 256-261, 1999.

4. Kulkarni A, Fiorenza F, Grimer RJ, et al: The results of endoprosthetic replacement for tumours of the distal humerus. J Bone Joint Surg 85-B: 24-243, 2003.

5. Hanna SA, David LA, Aston WLS, et al: Endoprosthetic replacement of the distal humerus following resection of bone tumours. J Bone Joint Surg 89-B: 1498-1503, 2007.

6. Schwab JH, Healey JH and Athanasian EA: Wide en bloc extra-articular excision of the elbow for sarcoma with complex reconstruction. J Bone Joint Surg 90-B: 78-83, 2008.

7. Koller H, Kolb K, Assuncao A, et al: The fate of elbow arthrodesis: Indications, techniques and outcome in fourteen patients. J Shoulder Elbow Surg 17: 293-306, 2008.

8. Dean GS, Holliger EH and Urbaniak JR: Elbow allograft for reconstruction of the elbow with massive bone loss. Long term results. Clin Orthop 341: 12-22, 1997.

9. Gianoutsos MP, Marsden FW, McCarthy SW, et al: Ulnar adamantionoma: en bloc excision and fibular osteoseptocutaneous free flap reconstruction. J Hand Surg 19-A: 495-499, 1994.

10. Kimura K, Tatezaki S, Ishii T, et al: Hemiarthroplasty of the elbow with a vascularized fibular graft after excision of Ewing's sarcoma of the proximal ulna: a case report. Jpn J Clin Oncol 32: 430-434, 2002.

11. Spira E and Lubin E: Extracorporeal irradiation of bone tumours: a preliminary report. Isr J Med Sci 4: 1015-1019, 1968.

12. Araki N, Myoui A, Kuratsu S, et al: Intraoperative extracorporeal autogenous irradiated bone grafts in tumor surgery. Clin Orthop 368: 196-205, 1999.

13. Chen WM, Haung CK, Chiang CC and Lo WH: Treatment of malignant bone tumours by extracorporeal irradiated autograftprosthetic composite arthroplasty. J Bone Joint Surg 84-B: 1156-1157, 2002.

14. Davidson AW, Hong A, McCarthy SW and Stalley PD: En-bloc resection, extracorporeal irradiation, and re-implantation in limb salvage for bony malignancies. J Bone Joint Surg 87-B: 851-857, 2005.

15. Uyttendaele D, De Schryver A, Claessens H, et al: Limb conservation in primary bone tumours by resection, extracorporeal irradiation and re-implantation. J Bone Joint Surg 70-B: 348-353, 1988.

16. Hatano H, Ogose A, Hotta T, et al: Extracorporeal irradiated autogenous osteochondral graft: a histological study. J Bone Joint Surg 87-B: 1006-1011, 2005.

17. Yamamoto T, Hitona $\mathrm{T}$ and Marui K: Reimplantation of autoclaved or irradiated cortical bones invaded by soft tissue sarcomas. Anticancer Res 22: 3685-3690, 2002.

18. Muramatsu K, Ihara K, Hashimoto T, et al: Combined use of free vascularised bone graft and extracorporeally-irradated autograft for the reconstruction of massive bone defects after resection of malignant tumour. J Plast Reconst Aesth Surg 60: 1-13, 1038, 2007.

19. Krieg AH, Davidson AW and Stalley PD: Intercalary femoral reconstruction with extracorporeal irradiated autogenous bone graft in limb-salvage surgery. J Bone Joint Surg 89-B: 366-371, 2007. 